\title{
DURABILITY OF BRIDGE STRUCTURAL ELEMENTS
}

Due to environmental actions evocated by the atmospheric behaviour, the material degradation processes are started. The effects of material deterioration due to corrosion cause the loss of cross-sectional or member resistance, but the limit state method does not directly reflect design and verification allowing for failures caused by this influence. The time-variant loss of steel and reinforced concrete moment cross-sectional resistances were computed respecting specific corrosion models to express the time-dependent approximation function taking into account effects of corrosion degradation. The paper presents the general principles of structural elements design for durability based on the limit state concept and their application in the case of moment cross-sectional resistance respecting the effects of corrosion degradation.

Keywords: Corrosion, corrosion models, cross-sectional resistance, numerical analyses, design for durability.

\section{Introduction}

The general approach to durability design is given by the standard [1] but the form of the procedure is not appropriate for design practice. The shortage of information related to the transformation processes of the environmental changes on the environmental actions, which is e.g. corrosion of steel, is the basic reason of this. On the other hand, the corrosion process has random character depending on many random variable parameters, therefore, its mathematical interpretation is somewhat complicated.

Generally, two approaches could be applied to verify durability of structures. The first approach is based on the concept of the design structural service life $t_{s}$ [2]. The second one is based on the limit state concept design considering effects of environmental actions in the following form

$P_{f}(t)=P\{R(t)-E(t) \leq 0\} \leq P_{f d}$,

where $E(t)$ represents the random variable time-dependent action effects and $R(t)$ is the random variable time-dependent structural member resistance. $E(t)$ and $R(t)$ are functions of random variables $X_{i}$, which are also time-dependent functions in relation to the models of material degradations.

\section{Corrosion of structural steel and reinforcement}

The mathematical description of the theoretical background of corrosion processes by means of differential equations is very complicated. Therefore, the development of semi-empirical models was preferred to apply for practical utilisation respecting the appropriate sophisticated level of approximation. This concept introduces need for systematic research and obtaining data related to the corrosion effects. Therefore, the most corrosion models are based on certain assumptions or results of experimental measurements. If the degradation influences of the corrosion process are known, the possibility of modelling corrosion effects using extrapolation of experimentally gained data exists and a mathematical model can be calibrated by means of them. Even though several long-term experimental investigations were performed in the past and many factors influencing corrosion process are known, the models of time-dependent prediction of corrosion loss are more or less simplified. Regarding random character of many parameters entering the corrosion process, the mathematical statistics and probability theory are the most appropriate approaches to describe the corrosion effects. At present, several corrosion models are known, which should be used to analyse corrosion effects from the viewpoint of structural reliability. The application in bridge engineering is not sufficiently verified, because the developed corrosion models based on laboratory tests are dependent on the modelling of actual environment by means of laboratory equipment. The review

\footnotetext{
* ' 'Josef Vican, ${ }^{1}$ Peter Kotes, ${ }^{2}$ Anna Spiewak, ${ }^{2}$ Malgorzata Ulewicz

${ }^{1}$ Department of Structures and Bridges, Faculty of Civil Engineering, University of Zilina, Slovakia

${ }^{2}$ Faculty of Civil Engineering, Czestochowa University of Technology, Czestochowa, Poland

E-mail: josef.vican@fstav.uniza.sk
} 
Probabilistic structural steel corrosion models

Table 1

\begin{tabular}{|l|c|c|c|}
\hline Author & Mean value $[\mathrm{mm}]$ & Standard deviation [mm] & Distribution \\
\hline Southwell-Melchers [3] & $0.084 t^{0.823}$ & $0.056 t^{0.823}$ & Normal \\
\hline Frangopol [4] & $0.03207 t^{0.5}$ & $0.00289 t^{0.045}$ & Normal \\
\hline Qin-Cui [5] & $1.67\left[1-\exp (-t / 9.15)^{1.97}\right]$ & $0.0674\left[1-\exp (-t / 0.181)^{0.0294}\right]$ & Normal \\
\hline Guedes- Soares [6] & \multicolumn{2}{|c|}{$d_{\text {corr }}(t)=1.5\left(1-e^{(t / 10)}\right)$ and $t$ is time in years } & - \\
\hline
\end{tabular}

of the most applied structural steel corrosion models describing the time-dependent material loss is presented in Table 1.

Examples of application of those corrosion models were introduced e.g. in [2, 7, 8 and 9].

In the case of the reinforcement corrosion, two models are usually used to describe the change of the reinforcement diameter in time due to corrosion taking into account uniform type of corrosion [ 10 and 11]. The process of degradation due to corrosion consists of two stages - passive stage and active stage. The passive stage means time $t_{0}$ from the beginning of the bridge operation, when degradation agents penetrate through the concrete cover up to the level of reinforcement, but reinforcement does not corrode. After that time, the concrete loses its passivation protection and the reinforcement corrosion starts - so called active stage $\left(\mathrm{t}-\mathrm{t}_{0}\right)$. The process of time-dependent change of reinforcement diameter can be described using following equations

$\phi(t)=\phi$, for time $t \leq t_{0}$,

$\phi(t)=\phi-0.0232 \cdot\left(t-t_{0}\right) \cdot i_{\text {corr }}$,

for time $t>t_{0}$, or

$\phi(t)=\phi-\left(t-t_{0}\right) \cdot r_{\text {corr }}$, for time $t>t_{0}$,

where $r_{\text {corr }}=$ corrosion rate $[\mu \mathrm{m} / \mathrm{year}] ; i_{\text {corr }}=$ corrosion current density $\left[\mu \mathrm{A} / \mathrm{cm}^{2}\right]\left(1 \mu \mathrm{A} / \mathrm{cm}^{2}\right.$ is equal to $11.6 \mu \mathrm{m} /$ year of corrosion $)$; $t=$ time [years]; $t_{0}=$ length of time of passive stage for longitudinal main reinforcement in years.

Formula (2b) was assumed according to [10] and formula (2c) was taken over from [11]. The length of the passive stage $t_{0}$ could be calculated according to the simplified model described in many references, e.g. [12 and 13] $t_{0}=\frac{c^{2}}{2 \cdot D}$

where $D=$ material constant $\left[\mathrm{mm}^{2} \cdot \mathrm{s}^{-1}\right]$.

\section{Moment resistance of steel cross-section considering corrosion}

To determine the effect of corrosion on the moment crosssectional resistance, the parametric study of six welded beams of the I-shape was performed. As random variables, the crosssectional dimensions $b_{\rho} t_{\rho} h_{w} t_{w}$ were considered together with random variable steel yield strength $f_{y^{\prime}}$. The basic statistical parameters of those random variables (mean $\mu$ and standard deviation $\sigma$ ) are presented in Table 2 and designations are defined in Fig. 1.

Standard deviations of those cross-sections were determined using standard tolerances $a$ according to standard [14] valid for tolerances of the web height and flange width and in accordance with standard [15] for tolerances of web and flange thickness under assumption that $95 \%$ of values of all realisations of the random variables normally distributed occurs in the interval

$\left\langle\mu_{x}-a ; \mu_{x}+a\right\rangle$

Then the standard deviation $\sigma$ is approximately possible to determine as $2 a$. According to above mentioned procedure, the standard deviations of the heights and widths of the investigated cross-sections were estimated.

$h \leq 900 \mathrm{~mm} \ldots \Delta h= \pm 3 \mathrm{~mm}_{\ldots} \ldots \sigma_{h w}=1.5 \mathrm{~mm}$
$h \leq 300 \mathrm{~mm} \ldots \Delta b= \pm 3 \mathrm{~mm}_{\ldots} . . \sigma_{b f}=1.5 \mathrm{~mm}$

Statistical characteristics of the parameters of analysed cross-sections

Table 2

\begin{tabular}{|c|c|c|c|c|c|c|c|c|c|c|c|c|}
\hline & \multicolumn{2}{|c|}{ Cross-section 1} & \multicolumn{2}{|c|}{ Cross-section 2} & \multicolumn{2}{|c|}{ Cross-section 3} & \multicolumn{2}{|c|}{ Cross-section 4} & \multicolumn{2}{|c|}{ Cross-section 5} & \multicolumn{2}{|c|}{ Cross-section 6} \\
\hline & $\mu$ & $\sigma$ & $\mu$ & $\sigma$ & $\mu$ & $\sigma$ & $\mu$ & $\sigma$ & $\mu$ & $\sigma$ & $\mu$ & $\sigma$ \\
\hline $\mathrm{f}_{\mathrm{y}}[\mathrm{MPa}]$ & 284.44 & 18.18 & 284.44 & 18.18 & 284.44 & 18.18 & 284.44 & 18.18 & 284.44 & 18.18 & 284.44 & 18.18 \\
\hline $\mathrm{b}_{\mathrm{f}}[\mathrm{mm}]$ & 150 & 0.987 & 150 & 0.987 & 175 & 0.987 & 175 & 0.987 & 200 & 0.987 & 200 & 0.987 \\
\hline $\mathrm{t}_{\mathrm{f}}[\mathrm{mm}]$ & 8 & 0.165 & 16 & 0.197 & 10 & 0.165 & 20 & 0.197 & 12 & 0.165 & 25 & 0.263 \\
\hline $\mathrm{h}_{\mathrm{w}}[\mathrm{mm}]$ & 284 & 0.987 & 268 & 0.987 & 380 & 0.987 & 360 & 0.987 & 476 & 0.987 & 450 & 0.987 \\
\hline $\mathrm{t}_{\mathrm{w}}[\mathrm{mm}]$ & 6 & 0.132 & 6 & 0.132 & 8 & 0.165 & 8 & 0.165 & 8 & 0.165 & 8 & 0.165 \\
\hline
\end{tabular}


Standard deviations of web and flange thickness are presented in Table 3.

The numerical calculation of the time-dependent moment cross-sectional resistance was processed using software Matlab, where the effect of the random variable cross-sectional dimensions and steel yield strength were taken into account. The normally distributed random variables were generated by means of Latin Hypercube Sampling (LHS) for 10000 samples.
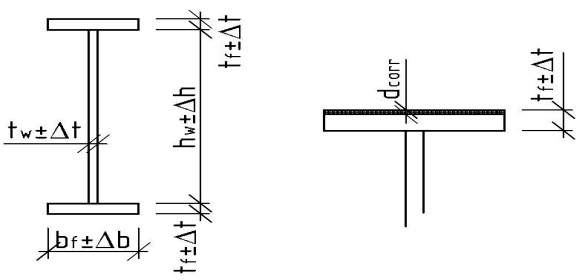

Fig. 1 Cross-sectional dimensions and considered tolerances

Standard deviations of cross-section thickness Table 3

\begin{tabular}{|c|c|c|c|}
\hline \multirow{2}{*}{$\begin{array}{c}\text { Nominal thickness } \\
{[\mathrm{mm}]}\end{array}$} & \multicolumn{2}{|c|}{ Limit values $[\mathrm{mm}]$} & \multirow{2}{*}{\begin{tabular}{c} 
Standard \\
deviation $\sigma_{\mathrm{t}}$ \\
\cline { 2 - 3 }$[\mathrm{mm}]$
\end{tabular}} \\
\hline $3 \leq t<5$ & -0.4 & 0.8 & 0.300 \\
\hline $5 \leq t<8$ & -0.4 & 1.1 & 0.375 \\
\hline $8 \leq t<15$ & -0.5 & 1.2 & 0.425 \\
\hline $15 \leq t<25$ & -0.6 & 1.3 & 0.475 \\
\hline $25 \leq t<40$ & -0.8 & 1.4 & 0.550 \\
\hline
\end{tabular}

The courses of the moment resistances were calculated using all above mentioned corrosion models (see Table 1) for lifetime of 100 years in dependence on the time $t$. Corrosion loss $d_{\text {corr }}$ according to individual models from Table 1 was implemented into the calculation by means of flange thickness reduction using formulae $t_{f r e d}=t_{f}-d_{\text {corr }}$, where $t_{f}$ is the flange thickness without corrosion loss. To determine the moment cross-sectional resistance considering the corrosion degradation due to flange corrosion, two approaches were applied.

For plastic time-dependent moment resistance $M_{p l}(t)$, the following equation was used

$$
M_{p l}=\left[t_{w} h_{w}^{2} / 4+b_{f}\left(h_{w}+t_{f}-d_{c o r r}\right)\left(t_{f}-d_{c o r r}\right)\right] f_{y},
$$

while the elastic time-dependent moment resistance was expressed by the equation $M_{e l}(t)$
Time-dependent course of the means of the plastic and elastic moment resistances of the cross-section 1 respecting the corrosion models according Table 1 are presented in Figs. 2 and 3.

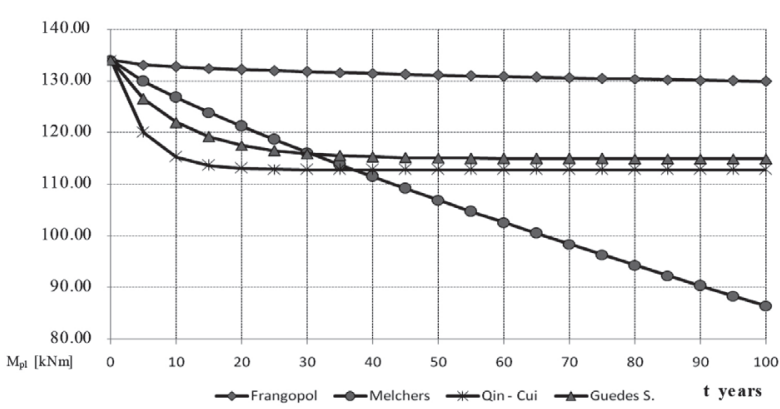

Fig. 2 Plastic cross-sectional moment resistances of cross-section

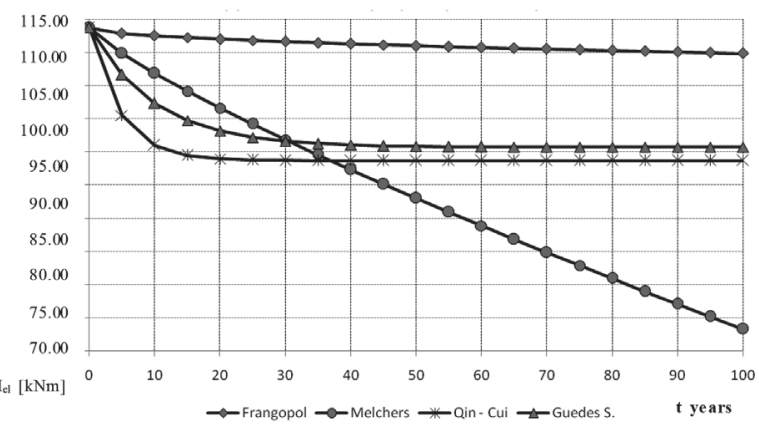

Fig. 3 Elastic cross-sectional moment resistances of cross-section

Time-dependent degradation function $F(t)$ was derived as the ratio of the moment resistance $R(t)$ of the cross-section degrading in time to the moment resistance $R_{0}$ at the beginning of the structure exploitation when it was not affected by the degradation effects

$F(t)=R(t) / R_{0}$

For further general utilisation, the degradation function $F(t)$ was approximated using software MATLAB by means of the following relation

$F(t)=a \cdot e^{-b \cdot t}+c$

The values of the coefficients $a, b, c$ determined using approximation proved very good compliance with courses of the approximated and actual degradation functions defined by the coefficient of regression $R^{2}$.

$M_{e l}=\left[\frac{\left(t_{w} h_{w}^{3} / 12+b_{f}\left(t_{f}-d_{c o r r}\right)^{3} / 6+b_{f}\left(t_{f}-d_{c o r r}\right)\left(h_{w}+t_{f}-d_{c o r r}\right)^{2} / 2\right)}{\left(h_{w} / 2+t_{f}-d_{\text {corr }}\right)}\right] f_{y}$ 
Concurrently, it was found that the value of the coefficient $b$ was constant for every corrosion model and the values of coefficients $a, c$ were changing while those coefficients were nearly independent on the cross-sectional classes defining the application of the plastic or elastic moment resistance.

Therefore, the given model of the prediction of corrosion loss should be applied from the viewpoint of environment type using the "degradation coefficient" $b$ and "shape coefficients" $a$, $c$, by means of which the time-dependent course of the degradation function of the cross-sectional resistance could be calculated for the designed cross-section and its lifetime.

Considering that degradation coefficient $b$ represents timedependent corrosion process depending on relevant corrosion model and when for coefficients $a$ and $c$ the relation $a+c=1$ is valid, then the shape coefficient $a$ is only necessary to determine according to following equation valid for Frangopol or Melchers corrosion models

$$
\begin{aligned}
& a=\frac{b_{f}\left(h_{w}+t_{f}-b_{0} t^{b_{1}}\right)\left(t_{f}-b_{0} t^{b_{1}}\right)-b_{f}\left(h_{w}+t_{f}\right) t_{f}}{W_{p l, 0}\left(e^{-b t}-1\right)}, \\
& \text { (9) }
\end{aligned}
$$

where coefficients $b_{0,} b_{1}$ are considered in accordance with the appropriate Frangopol or Melchers corrosion models (0.03207, 0.5 or $0.084,0.823$ ). The resulting value of the coefficient $a$ is the minimum value in time interval within the element lifetime. The approach presented above is relatively complicated for practical utilisation. Therefore, it would be appropriate to process the value of the coefficient $a$ in tabular form.

The Qin-Cui and Guedes-Soares corrosion models enable a more simple calculation of the coefficient $a$. Its value could be directly obtained when the corrosion loss determined according to the appropriate model in time $t=\infty$ is taken away from the relation (9). Then, the relation (9) should be adjusted in the following form

$a=\frac{b_{f}\left(h_{w}+t_{f}-d_{c o r r, t=\infty}\right)\left(t_{f}-d_{c o r r, t=\infty}\right)-b_{f}\left(h_{w}+t_{f}\right) t_{f}}{W_{p l, 0}\left(e^{-b t}-1\right)}$.

The value of $d_{\text {corr, } t=\infty}=1.67 \mathrm{~mm}$ for Qin-Cui model and $d_{\text {corr }, t=\infty}=1.50 \mathrm{~mm}$ for Guedes-Soares corrosion model should be substituted into the equation (10). To prove the correctness of the assumptions related to the coefficients $a, b$ and derivation of the general solution, the new parametric study was worked up for 2500 beams having welded I-shaped cross-section, whose crosssectional characteristics and yield strength were considered as random variables.

It follows from the new parametric study that the degradation coefficient $b$ has the constant value for given corrosion model and values of coefficients $a, c$ were only changing. Degradation coefficient $b$ is dependent on the relevant corrosion model and also on the environmental condition. It is also clear that calculation of the shape coefficient $a$ could be simplified using the following relation $a=\frac{b_{f}\left(2 t_{f}+h_{w}\right)}{W_{p l, 0}} \alpha_{\text {corr.model }}$

where $\alpha_{\text {corr.model }}$ introduces the corrosion coefficient given in Table 4 according to the appropriate corrosion model.

Final values of the degradation and corrosion coefficients $\mathrm{b}$ and $\alpha_{\text {corrmodel }}$

Table 4

\begin{tabular}{|l|c|c|}
\hline \multirow{2}{*}{ Corrosion model } & \multicolumn{2}{|c|}{ Coefficient } \\
\cline { 2 - 3 } & $b$ & $\alpha_{\text {corr.model }}$ \\
\hline Frangopol & 0.0194 & $3.278 \mathrm{E}-04$ \\
\hline Melchers & 0.0055 & $8.460 \mathrm{E}-03$ \\
\hline Qin-Cui & 0.2158 & $1.655 \mathrm{E}-03$ \\
\hline Guedes-Soares & 0.1003 & $1.490 \mathrm{E}-03$ \\
\hline
\end{tabular}

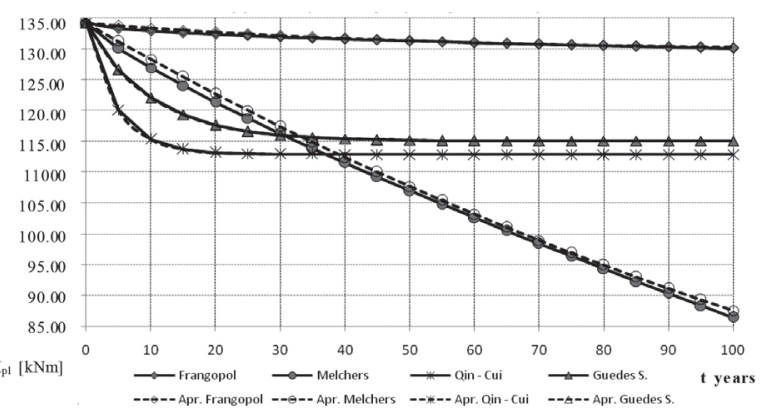

Fig. 4 Comparison of numerically obtained time-dependent course of plastic moment resistance to the resistance calculated according to proposed analytical relation (12)

Finally, the time-dependent moment resistance of I-shaped cross-section with degradation of the both flanges could be determined according to following equation

$M_{R d}(t)=M_{R d, t=0}\left[1+a\left(e^{-b t}-1\right)\right]$,

where value of the coefficient $a$ should be calculated using equation (11) and degradation coefficients $b, \alpha_{\text {corr.model should }}$ be considered in accordance with Table 4.The comparison of the numerically determined courses of the plastic moment resistance of the cross-section 1 to calculations according to relation (12) for individual corrosion models is introduced in Fig. 4. The very good compliance of the analytical model with numerical analyses can be identified. 


\section{Moment resistance of reinforced concrete cross- section considering reinforcement corrosion}

Concrete structures shall be adequately safe against failure and must also exhibit satisfactory performance in service. The internal forces as bending moments $M$ and shear forces $V$ are considered as the relevant structural response to actions. Vertical bending seems to be the main action effect determining the cross-sectional dimensions and arrangement of the longitudinal reinforcement, which are firstly contemplated to provide the necessary moment resistance.

Bending limit state comes into being when the limit strain is achieved at least in one of the materials (concrete in compression or reinforcement in tension) [16 and 17]. In the case of girder bridges, the bridge deck is always connected with beams, therefore, the cross-section is considered as flanged beam (crosssection of the $\mathrm{T}$ shape). The time-dependent moment resistance $M_{R d}(t)$ of the reinforced concrete flanged beam is given in accordance with standard [18] by formula

$$
\begin{aligned}
& M_{R d}(t)=F_{s}(t) \cdot z(t)=A_{s 1}(t) \cdot f_{y d} \cdot z(t)= \\
& A_{s 1}(t) \cdot f_{y d} \cdot\left(\left[h-c-\frac{\phi(t)}{2}\right]-\frac{A_{s 1}(t) \cdot f_{y d}}{2 \cdot b_{e f f} \cdot f_{c d}}\right)
\end{aligned}
$$

where $F_{s}(t)$ is the time-dependent force in tensioned reinforcement changed due to corrosion, $z(t)$ is the time-dependent lever of internal forces, $f_{v d}$ is the design steel yield strength, $f_{c d}$ is the design compressive strength of concrete, $h$ is the cross-sectional height, $h$ is the height of slab (beam flange), $b$ is the beam cross-sectional width, $b_{\text {eff }}$ is the effective cross-sectional width, $c$ is the concrete cover thickness, $n$ is the number of longitudinal reinforcements in cross-section, $A_{s l}(t)$ is the time-dependent reinforcement crosssectional area changed due to reinforcement corrosion and $\varphi(t)$ is the longitudinal reinforcement diameter (see Fig. 5).

As it was presented in [19 and 20], equation (13) could be modified into its final form for moment resistance depending only on time

$$
\begin{aligned}
& M_{R d}(t)=M_{R d}(0)+k_{1} \cdot\left(t-t_{0}\right)+k_{2} \cdot\left(t-t_{0}\right)^{2}+ \\
& +k_{3} \cdot\left(t-t_{0}\right)^{3}+k_{4} \cdot\left(t-t_{0}\right)^{4}
\end{aligned}
$$

where $k_{1,} k_{2,} k_{3,} k_{4}$ are the parameters depending on material and geometrical characteristics with their physical significance

$$
\begin{aligned}
& k_{4}=A \cdot 0.0232^{4} \cdot i_{\text {corr }}^{4}, \text { or } k_{4}=A \cdot r_{\text {corr }}^{4}, \\
& k_{3}=(4 \cdot A \cdot \phi+B) \cdot 0.0232^{3} \cdot i_{\text {corr }}^{3}, \\
& \text { or } k_{3}=(4 \cdot A \cdot \phi+B) \cdot r_{\text {corr }}^{3},
\end{aligned}
$$$$
k_{2}=\left(6 \cdot A \cdot \phi^{2}+3 \cdot B \cdot \phi+C\right) \cdot 0.0232^{2} \cdot i_{c o r r}^{2}
$$$$
\text { or } k_{2}=\left(6 \cdot A \cdot \phi^{2}+3 \cdot B \cdot \phi+C\right) \cdot r_{\text {corr }}^{2} \text {, }
$$$$
k_{1}=\left(4 \cdot A \cdot \phi^{3}+3 \cdot B \cdot \phi^{2}+2 \cdot C \cdot \phi\right) \cdot 0.0232 \cdot i_{\text {corr }} \text {, }
$$$$
\text { or }
$$$$
k_{1}=\left(4 \cdot A \cdot \phi^{3}+3 \cdot B \cdot \phi^{2}+2 \cdot C \cdot \phi\right) \cdot r_{c o r r}
$$

where $A, B, C$ are the time-independent parameters

$$
\begin{aligned}
& A=-\frac{\pi^{2} \cdot n^{2} \cdot f_{y d}^{2}}{32 \cdot b_{\text {eff }} \cdot f_{c d}} \\
& B=-\frac{\pi \cdot n \cdot f_{y d}}{8} \\
& C=\frac{\pi \cdot n \cdot f_{y d} \cdot(h-c)}{4}
\end{aligned}
$$
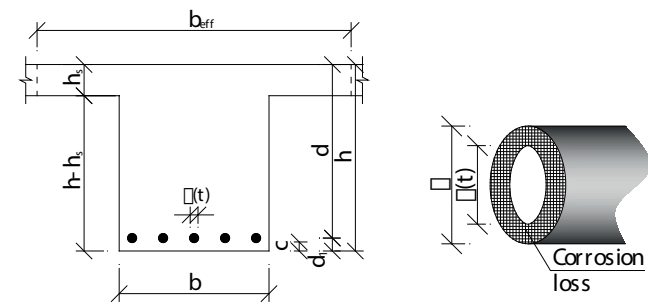

Fig. 5 Flanged beam - denotation

The parametric study was performed in accordance with the

\begin{tabular}{|c|c|c|c|}
\hline Material characteristics & Notation & Unit & Value \\
\hline $\begin{array}{l}\text { Strength of concrete in } \\
\text { compression }\end{array}$ & $\mathrm{f}_{\mathrm{cd}}$ & N.mm ${ }^{2}$ & 20.0 \\
\hline Yield strength of reinforcement & $f_{y d}$ & N.mm ${ }^{2}$ & 179.23 \\
\hline Height of cross-section & $\mathrm{h}$ & $\mathrm{m}$ & 0.837 \\
\hline Width of cross-section & $\mathrm{b}$ & $\mathrm{m}$ & 0.322 \\
\hline Effective width of cross-section & $b_{\text {eff }}$ & $\mathrm{m}$ & 1.545 \\
\hline Concrete cover thickness - main & $\mathrm{c}$ & $\mathrm{mm}$ & 29.6 \\
\hline Concrete cover thickness - stirrups & $\mathrm{c}_{\mathrm{s}}$ & $\mathrm{mm}$ & 15.6 \\
\hline Number of bars (reinforcement) & $\mathrm{n}$ & $\overline{p c s}$ & 7 \\
\hline Slab height & $h_{s}$ & $\mathrm{~m}$ & 0.186 \\
\hline Bar diameter - main longitudinal & $\varphi$ & $\mathrm{m}$ & 0.030 \\
\hline Bar diameter - stirrups & $\varphi_{\mathrm{s}}$ & $\mathrm{m}$ & 0.014 \\
\hline \multirow{4}{*}{ Corrosion current density } & \multirow{4}{*}{$\mathrm{i}_{\text {corr }}$} & \multirow{4}{*}{$\begin{array}{l}\mu \mathrm{A} / \\
\mathrm{cm}^{2}\end{array}$} & 0.5 \\
\hline & & & 1.0 \\
\hline & & & 3.0 \\
\hline & & & 5.0 \\
\hline Material constant & $\mathrm{D}$ & $\mathrm{mm}^{2} \cdot \mathrm{s}^{-1}$ & $4.82 \cdot 10^{-7}$ \\
\hline
\end{tabular}
approach described above.

\section{Experimental application}

The influence of longitudinal reinforcement corrosion on moment resistance of the bridge structural element was investigated. The reinforced concrete flanged beam subjected to bending with material and geometrical characteristics given in Table 5 obtained from measurement on the real bridge structure was used.

Material characteristics used in parametric study Table 5 
From the results of the bridge diagnostics follows that the concrete of $\mathrm{C} 30 / 37$ was used and the beams are reinforced with the rebar of $\mathrm{A}(10210)$ in two layers ( $5 \phi$ in the lower layer and $2 \phi$ in the upper layer). The design lifetime for bridge structural element is equal to $T_{d}=100$ years. Firstly, the length of time of passive stage $t_{0}$ for longitudinal reinforcement was calculated using formula (3). Then, the active stage $\left(t-t_{0}\right)$ was calculated according to formula (2b) in the parametric study. Due to the parametric study, various corrosion current densities $\left(i_{\text {corr }}\right)$ were considered. The influence of the corrosion on the time-dependent moment resistance of the reinforced concrete flanged beam is shown in Fig. 6.

The length of the passive stage for main longitudinal reinforcement was calculated as $\mathrm{t}_{0}=28.8$ years (for $\mathrm{D}=4.82 \cdot 10^{-7}$ $\left.\mathrm{mm}^{2} \mathrm{~s}^{-1}\right)$. The basic value of the moment resistance at time $\mathrm{t}=0$ year is equal to $\mathrm{M}_{\mathrm{Rd}}(\mathrm{t}=0)=689.621 \mathrm{kNm}$. Hypothetically, the decrease of moment resistance during the whole lifetime was $5.3 \%$ in the case of $i_{\text {corr }}=0.50 \mu \mathrm{A} / \mathrm{cm}^{2}$ (small aggressive environment), $10.4 \%$ for $\mathrm{i}_{\text {corr }}=1.00 \mu \mathrm{A} / \mathrm{cm}^{2}$ (average aggressive environment), but as much as $29.7 \%$ for $\mathrm{i}_{\text {corr }}=3.00 \mu \mathrm{A} / \mathrm{cm}^{2}$ (very aggressive environment in Slovakia) or $46.7 \%$ for $\mathrm{i}_{\text {corr }}=5.00 \mu \mathrm{A} /$ $\mathrm{cm}^{2}$ (very aggressive environment recommended for coastal areas).

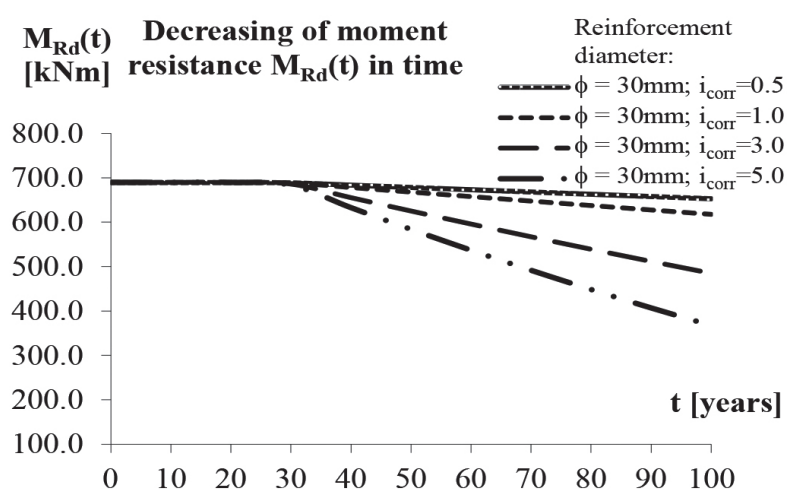

Fig. 6 Change of moment resistance $M_{R d}(t)$ in time

of reinforced concrete beam due to reinforcement corrosion

Diagnostics of the investigated bridge structural element was performed in 2006. At that time, the bridge was approximately 65 years old. The corrosion caused the rebar diameter loss from the initial value $30 \mathrm{~mm}$ to average value $29.37 \mathrm{~mm}$ (the minimal measured value was $28.7 \mathrm{~mm}$ ). Now, it is possible to calculate backwards from the formulas $(2 b, 2 c)$ the length of time, i.e. in how many years reinforcement would corrod from the basic diameter of $\phi=30 \mathrm{~mm}$ to average value $\phi=29.37 \mathrm{~mm}$ depending on environmental aggressiveness $\left(\mathrm{i}_{\text {corr }}\right)$. That length of time is called an active stage. The formulas $(2 b)$ or $(2 c)$ are changed after modification to

$t=\frac{\phi-\phi(t)}{0.0232 \cdot i_{\text {corr }}}+t_{0}$, or $t=\frac{\phi-\phi(t)}{r_{\text {corr }}}+t_{0}$.
Using formula (22a) and if $t_{0}=0$, the reinforcement diameter changes due to corrosion from the basic diameter $\phi=30 \mathrm{~mm}$ to the average value $\phi=29.37 \mathrm{~mm}$ would be 54.31 years (for $i_{\text {corr }}=0.50 \mu \mathrm{A} / \mathrm{cm}^{2}$ ), 27.16 years (for $i_{\text {corr }}=1.0 \mu \mathrm{A} / \mathrm{cm}^{2}$ ), 9.05 years (for $i_{\text {corr }}=3.0 \mu \mathrm{A} / \mathrm{cm}^{2}$ ), or 5.43 years (for $i_{\text {corr }}=5.0 \mu \mathrm{A} / \mathrm{cm}^{2}$ ).

The corresponding length of the passive stage $t_{0}$ can be obtained by modification of formulas $(22 \mathrm{a}, 22 \mathrm{~b})$, if $t$ is equal to age of the bridge ( $t=65$ years). The shortest length of the passive stage was obtained for $\mathrm{i}_{\text {corr }}=0.50 \mu \mathrm{A} / \mathrm{cm}^{2}$ and was equal to $t_{0}=10.69$ years. The lengths of time of passive stages are equal to $\mathrm{t}_{0}=37.84$ years for $\mathrm{i}_{\text {corr }}=1.00 \mu \mathrm{A} / \mathrm{cm}^{2}, \mathrm{t}_{0}=55.95$ years for $\mathrm{i}_{\text {corr }}=3.00 \mu \mathrm{A} / \mathrm{cm}^{2}$ and $\mathrm{t}_{0}=59.57$ years for $\mathrm{i}_{\text {corr }}=5.00 \mu \mathrm{A} / \mathrm{cm}^{2}$. Now, it is possible to predict the moment resistance change of reinforced concrete flanged beam up to the end of design lifetime $T_{d}=100$ years. The results are shown in Fig. 7.

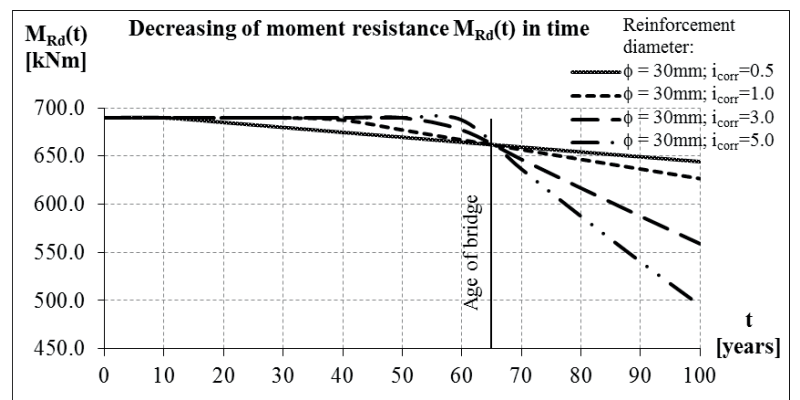

Fig. 7 Prediction of moment resistance change $M_{R d}(t)$ in time of the reinforced concrete bridge beam due to reinforcement corrosion

\section{Conclusions}

The paper presents the results of the research concerning the influence of the corrosion of the structural steel or reinforcement on the time-dependent moment cross-sectional resistances of I-shaped cross-section and also on the cross-section of the flanged bridge beam. Two approaches are introduced related to the expressing the effect of corrosion on the moment cross-sectional resistance. The first approach is based on the assumption taking into account the effect of corrosion of structural steel using approximated degradation function $F(t)$ and multiple it by the moment cross-sectional resistance in time $t=0$ to obtain the actual moment resistance in time $t$ respecting the known corrosion models. The second approach was derived to allow for effect of reinforcement corrosion on the moment cross-sectional resistance of reinforced concrete flange beam respecting the known corrosion models valid for reinforcement corrosion. It follows from result analysis that the reinforcement corrosion has significant influence on change of resistances in time. 


\section{Acknowledgement}

The research was supported by the European Regional Development Fund and the Slovak state budget for the project
"Research Centre of University of Zilina”, ITMS 26220220183 and by the Slovak Research and Development Agency under contract No. APVV-14-0772 and also by the project SK-PL-20150004 in frame of bilateral cooperation.

\section{References}

[1] ISO DIS 13823: General Principles on the Design of Structures for Durability. ISO/TC 98/SC 2.

[2] VICAN, J., SYKORA, M.: Design of Compression Members for Durability. Communications - Scientific Letters of University of Zilina, vol. 11, No. 4, pp. 9-15.

[3] MELCHERS, R. E.: Corrosion Uncertainty Modelling for Steel Structures. J. of Constructional Steel Research, Elsevier, 1999.

[4] AKGUL, F., FRANGOPOL, D., M.: Lifetime Performance Analysis of Existing Steel Girder Bridge Superstructures. J. of Structural Engineering, v. 130, No. 12, pp. 1875-1888.

[5] QIN, S., CUI, W.: Effect of Corrosion Models on the Time-Dependent Reliability of Steel Plated Elements, Marine Structures, Elsevier, 2003.

[6] GUEDES SOARES, C., GARBATOV, Y.: Reliability of Maintained, Corrosion Protected Plates Subjected to Non-Linear Corrosion and Compressive Loads, Marine Structures, Elsevier, 1999.

[7] VICAN, J., KURCIK, F.: Corrosion Effect on Truss Bridge Compression Chord Reliability. Intern. Conference "Bridges in Danube Basin 2007”, Budapest 2007, pp. 449-460.

[8] VICAN, J., SYKORA, M.: Numerical Analysis of the Bridge Orthotropic Deck Time-Dependent Resistance, Communications Scientific letters of the University of Zilina, vol. 15, No. 3, pp.112-118, ISSN 1335-4205.

[9] KVOCAK, V., VARGOVA, R., BEKE, P., TERPAKOVA, E.: Effects of Atmospheric Corrosion on the Car Park Roof Structure, Communications - Scientific letters of the University of Zilina, vol. 14, No. 1, pp. 80-87, ISSN 1335-4205.

[10] ANDRADE, C., SARRIA, J., ALONSO, C.: Corrosion Rate Field Monitoring of Post-Tensioned Tendons in Contact with Chlorides. Durability of building materials and components, Stockholm, 1996, pp. 959-967.

[11] THOFT-CHRISTENSEN, P.: A Reliability Based Expert System for Bridge Maintenance, Tekno Vision Conference, 1992, Denmark.

[12] BILCIK, J.: Prediction of Service Life with regard to Reinforcement Corrosion, Slovak J. of Civil Engineering, vol. 2-3, 1998, pp.3438.

[13] Ceb-Fip Model Code 2010, 2011. Special Activity Group 5, 653 p.

[14] STN EN 1090-2 + A1: Execution of Steel Structures and Aluminium Structures - Part 2: Technical Requirements for Steel Structures. Slovak Office for Standards, Metrology and Testing, Bratislava, 2012.

[15] STN EN 10029: Hot-rolled steel plates $3 \mathrm{~mm}$ thick or above - Tolerances on dimensions and shape. Slovak Office for Standards, Metrology and Testing, Bratislava, 2011.

[16] HALVONIK, J., BENKO, V., HUBOVA, O., SOKOL, M., STUJBEROVÁ, M., BORZOVIC, V.: Design of Bearing Structures of Constructions. Basis of Design and Actions, $1^{\text {st }}$ ed. (in Slovak), STU : SvF : Bratislava, 2009. 144 p.

[17] BENKO, V., FILLO, L., KENDICKY, P., KNAPCOVA, V.: Experimental and Numerical Analysis of Concrete Slender Columns by Stability Failure, Applied Mechanics and Materials : selected, peer reviewed papers from the Engineering Mechanics 2015, Svratka, 11. - 14. 5. 2015, vol. 821, 2016, pp. 747-752.

[18] STN EN 1992-2: Eurocode 2: Design of Concrete Structures - Part 2: Concrete Bridges, Design and Detailing Rules + National Annex. Slovak Office for Standards, Metrology and Testing, Bratislava, 2007.

[19] KOTES, P., VICAN, J., IVASKOVA, M.: Influence of Reinforcement Corrosion on Reliability and Remaining Lifetime of RC Bridges. Materials Science Forum, 2015, ISSN: 1662-9752, vol. 844, pp. 89-96.

[20] KOTES, P., DUBALA, K., SELEJDAK, J.: Influence of Reinforcement Corrosion on Moment Load-Carrying Capacity of RC Bridge Girder Subjected To Bending. Proc. of the $11^{\text {th }}$ European conference of young researchers and scientists "Transcom 2015", University of Zilina, June 22-24, pp. 52-57. 